
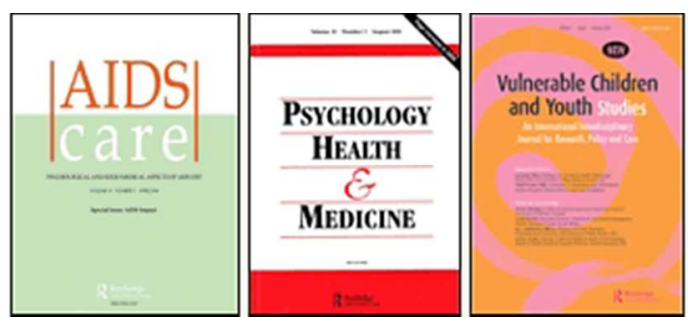

\title{
The pain of low status: The relationship between subjective socioeconomic status and analgesic prescriptions in a Scottish community sample
}

\begin{tabular}{|r|l|}
\hline Journal: & $\begin{array}{l}\text { AIDS Care - Psychology, Health \& Medicine - Vulnerable Children and Youth } \\
\text { Studies }\end{array}$ \\
\hline Manuscript ID: & PHM-2014-06-0412.R2 \\
\hline Journal Selection: & Psychology, Health \& Medicine \\
\hline Keywords: & $\begin{array}{l}\text { Socio-economic Status, Pain, Psychosocial determinants of health, } \\
\text { Analgesics, Subjective socio-economic status }\end{array}$ \\
\hline \multicolumn{2}{|l}{} \\
\hline
\end{tabular}

SCHOLARONE ${ }^{m}$

Manuscripts 
The pain of low status: The relationship between subjective socioeconomic status and analgesic prescriptions in a Scottish community sample

Word Count (exc. Title Page, Abstract, References, and Tables): 2,999. 


\begin{abstract}
There is a strong positive relationship between objective measures of socioeconomic status (OSS) and general health. However, there is an increasing interest in the relationship between health and subjective socioeconomic status (SSS), which describes one's perceived rank in relation to the rest of society, based on factors such as income, occupation, and education. While the relationship between SSS and general health is well-established, the relationship between SSS and pain has received little attention. Gathering both self-report questionnaire data and General Practitioner medical data from a large representative community sample in Scotland between 2012 and $2013(N=1824)$, we investigated the relationship between SSS and prescriptions for analgesic drugs. We found that higher levels of SSS significantly predicted lower odds of participants having been prescribed at least one analgesic drug in the previous six months. We obtained this result even after controlling for OSS-related variables (education, occupational status, and geographical location) and demographic variables (age and gender). This suggests that, just like the relationship between SSS and general health, SSS has important effects on pain that go beyond the influence of OSS.
\end{abstract}

Keywords: socioeconomic status; subjective socioeconomic status; objective socioeconomic status; pain; psychosocial determinants of pain; analgesics; health. 


\section{Introduction}

Research indicates that socioeconomic status (SES) is an important predictor of mortality and morbidity. Low SES increases susceptibility to most illnesses, including diabetes, arthritis, and cardiovascular diseases (e.g., Adler \& Snibbe, 2003).

Although the SES-health relationship is well-supported, researchers have become aware of the potential limitations of measuring SES objectively (via income, occupation, and education). For instance, it may not be useful for retired individuals who completed their education long ago (Wright \& Steptoe, 2005). However, an alternative to objective socioeconomic status (OSS) is subjective socioeconomic status (SSS). SSS is "a person's belief about his location in a status order" (Davis, 1956, p. 154), and is usually measured with an image of a ladder featuring ten rungs. The participant considers their personal income, occupational status, and educational attainment in relation to the rest of society, and indicates the rung that best represents their status (Adler, Epel, Castellazzo, \& Ickovics, 2000).

SSS seems to be a more nuanced measure than OSS, as it involves assessment of past events, current circumstances, and future prospects (e.g., Adler et al., 2008). This means that SSS might often be a preferable measure to OSS.

\section{SSS and Health}

Strong SSS-health associations have been reported, and these remain even once OSS has been accounted for. Singh-Manoux et al. (2005) found both SSS and OSS were independently linked to self-rated health, but only SSS remained a significant predictor when both were included in the model. SSS was also better at predicting health status decline, suggesting that SSS assesses future prospects, while OSS cannot. Additionally, Ostrove, Adler, Kupperman, and Washington (2000) found SSS was significantly related to self-rated 
health in pregnant women, and the relationship remained for both Whites and Chinese once objective measures were accounted for.

There is also evidence of the link between SSS and objective health measures. Cohen et al. (2008) found higher SSS reduced participants' likelihood of developing common cold, and that this was independent of OSS. Adler et al. (2000) found low levels of SSS amongst healthy White women to be related to higher abdominal fat distribution and higher cortisol reactivity to stressors, both of which relate to ill-health. Similarly, Wright and Steptoe (2005) found a relationship between low SSS and higher cortisol awakening response (which affects disease susceptibility), which remained after controlling for other important variables. Low SSS (but not low OSS) has even been linked to reduced grey matter in the perigenual anterior cingulate cortex, which controls stress reactions (Gianaros et al., 2007).

Moreover, there is now research that links SSS to an array of specific illnesses, including angina, diabetes, respiratory illness, heart disease, mental dysfunction, and obesity (e.g., Singh-Manoux et al., 2003; Honjo et al., 2014; Goodman et al., 2003; Goodman et al., 2001). However, there is one health-related issue that is well-studied in the OSS literature, but has received little attention in the SSS literature, even though it is something virtually all humans experience: pain.

\section{OSS and Pain}

Pain has a strongly negative impact on industrialized societies: backache alone costs the UK over 12 billion pounds per annum (SIGN, 2013). While pain relates to various factors, studies have highlighted the important role OSS plays in dictating both the experience of pain and the extent to which it affects life quality.

This work generally examines the relationship between OSS and chronic pain, such as backache, musculoskeletal pain, and headaches/migraines (Gerstle, All, \& Wallace, 2001). 
Saastamoinen, Leino-Arjas, Laaksonen, and Lahelma (2005) found employees in Helsinki with relatively low educational attainment and occupational class were most at risk of chronic/disabling pain, while Dorner et al. (2011) report that people with lower OSS not only experience more severe pain, but also greater pain-related disability when severity is controlled for. Gerstle et al. (2001) found that amongst Americans with chronic pain, low OSS was associated with lower perceived life quality.

\section{Current Study}

We wished to expand the well-established literature on OSS and pain by investigating the SSS-pain relationship. Although SSS is clearly linked with painful diseases like angina (Singh-Manoux et al., 2003), little work has explicitly investigated SSS's relationship to pain. Moreover, most research involves self-rated pain measures, which risk reporting bias (e.g., Macleod, Smith, Metcalfe, and Hart, 2005). However, Soares and Grossi (1999) compared analgesic use in Turkish (lower OSS) and Swedish (higher OSS) patients with musculoskeletal pain, and found Turkish patients consumed more analgesics. With these observations in mind, we wished to examine the SSS-pain relationship in a large representative sample, using analgesic prescriptions as an objective measure. Considering previous research, we predict a negative SSS- prescriptions relationship, even after controlling for OSS and demographic variables.

\section{Method}

\section{Participants and Procedure}

This study is based on the Scottish portion of Wave 1 of the two-wave Health in Groups project. Five General Practitioner (GP) surgeries situated across Scotland posted participation invitations to all their patients for whom the study was deemed suitable (individuals over 18 without terminal illnesses or conditions like dementia). No incentives 
were provided. Interested patients $(N=2508 ; 11.85 \%$ response rate $)$ returned a reply slip included with the invitation. They received a consent form and questionnaire, which were returned by 1824 patients (henceforth participants; 771 males, 1053 females, $M_{\text {age }}=57.55$ years, $S D=14.57$, range: $18-97$ years). The first author then visited the GP surgeries around 3 months after invitations were posted, and extracted health data for each participant from the databases. This paper only deals with variables and data that are relevant to the present topic: for further analyses, see Sani, Madhok, Norbury, Dugard, and Wakefield (2014).

\section{Questionnaire Measures}

\section{Subjective Socioeconomic Status}

Participants were presented with the image of a ten-rung ladder and were asked to "Think of this ladder as representing where people stand in the UK. At the top of the ladder are the people who are the best off - those who have the most money, the most education and the most respected jobs. At the bottom are the people who are the worst off - those who have the least money, the least education and the least respected jobs or no jobs at all. The higher up you are on this ladder the closer you are to the people at the very top, the lower you are the closer you are to the people at the very bottom. Place a large " $\mathrm{X}$ " on the rung where you think you stand at this point in your life, relative to other people in the UK." This measure is adapted from Adler et al. (2000). Participants were given a value from 1-10 (top rung = 10; higher values $=$ higher SSS). An " $\mathrm{X}$ " between two rungs was counted as sitting on the higher rung. A categorical variable was created (henceforth subjective socioeconomic status), where scores from one to three were categorized as 1 (low SSS), four to six were categorized as 2 (medium SSS), and seven to ten were categorized as 3 (high SSS).

\section{Demographic Variables}


As well as recording gender $($ female $=0$, male $=1)$ and age, we also measured education and occupational status. We coded participants with up to high school education as 0 and participants with any qualification above high school as 1 . We coded employed participants as 1 and non-employed participants (unemployed, retired, students, or housewives/househusbands) as 0 .

Since participants' GP surgeries- and therefore participants themselves- were located in areas with varying neighbourhood SES levels; which affects health; e.g., Chen \& Paterson, 2006, and pain specifically; Fuentes, Hart-Johnson, \& Green, 2007; Aggarwal, Macfarlane, \& Macfarlane, 2003; we created a categorical variable to indicate the GP surgery the participant attended. Three surgeries were in the same location, so we combined these into one category (Location 2). Locations 3 and 1 have the highest and lowest SES respectively, while Location 2 has medium SES (i.e., larger value = higher status; Scottish Government, 2012).

\section{Medical Data}

\section{Analgesic Prescriptions}

The number of prescriptions for analgesics each participant had received in the six months prior to the day of data collection was recorded. 'Analgesics' were defined as any drug appearing in Section 4.7 (“Analgesics”) of the British National Formulary (Joint Formulary Committee, 2012). A binary variable (analgesics) was created, where $0=$ none prescribed, and $1=$ at least one prescribed.

\section{Results}

\section{Cross Tabular Analyses}

Table 1 reports analgesics frequencies as a function of SSS, together with the chi-square statistic. As SSS increased, the number of participants prescribed analgesics decreased, with 
the relationship following a clear gradient: $25.00 \%$ of respondents in the lowest SSS category had been prescribed analgesics, compared to $23.20 \%$ and $15.95 \%$ in the medium and highest categories respectively. The association was significant, $\chi^{2}(2, N=1773)=16.04, p<.001$.

\section{(TABLE 1)}

Table 2 reports analgesics frequencies as a function of gender, education, occupational status, and GP location, together with the chi-square statistics. Participants with education above high school were less likely to have been prescribed analgesics than those with education up to high school $\chi^{2}(1, N=1802)=46.05, p<.001$. Employees were less likely to have been prescribed analgesics than non-employees $\chi^{2}(1, N=1812)=84.00, p<.001$. GP location was also significantly associated with analgesics, $\chi^{2}(2, N=1815)=37.95, p<.001$, with participants from Locations 1 (lowest SES) and 3 (highest SES) being most and least likely to have been prescribed respectively. No links emerged regarding gender.

\section{(TABLE 2)}

\section{Logistic Regression Analysis}

We performed a binary logistic regression to investigate the effects of SSS, age, gender, level of education, occupational status, and GP surgery on the odds that participants have been prescribed at least one analgesic in the last six months.

\section{Assumptions}

Although many of the variables correlated significantly with each other, correlations were generally small (Table 3). Moreover, the logit was linear, no evidence of multicollinearity was evident (based on Tolerance and Variance Inflation Factor values), and outliers comprised below $5 \%$ of all cases. Although $N=1824$, only individuals with data for all variables $(n=1765)$ were included.

\section{(TABLE 3)}




\section{Analysis}

The results (Table 4) revealed the full model was significant, $\chi^{2}(6, N=1765)=150.98, p$ $<.001$. SSS contributed significantly to predicting lower odds of participants having been prescribed analgesics, $\mathrm{OR}=0.80$. Odds increased with age, $\mathrm{OR}=1.02$, and participants possessing education above high school had smaller odds than those with up to high school education, $\mathrm{OR}=0.61$. Employees also had smaller odds than non-employees $\mathrm{OR}=0.43$. Finally, participants attending GPs in higher-status locations had lower odds than those attending lower-status locations, $\mathrm{OR}=0.60$. Gender had no effect.

\section{(TABLE 4)}

\section{Discussion}

The results confirm our predictions: higher SSS significantly predicted lower odds of being prescribed analgesics, even after controlling for OSS-related variables (education, occupational status, and location) and demographic variables (age and gender). This suggests that, just like the SSS-general health relationship, SSS has effects on pain that transcend OSS's influence.

\section{Potential Explanations}

Numerous researchers have proposed explanations for the SSS-general health relationship. Much of this work is inspired by studies showing that subordinate animals often suffer from ill-health (Eisermann, 1992; Devoino, Alperina, Kudryavtseva, \& Popova, 1993), which Saplosky (2004) argues is because they usually experience more stress than dominant animals. Saplosky also suggests the closest human equivalent to animal rank is socioeconomic status, thus implying that stress might be central to the SSS-health relationship. While some stress (particularly for individuals with very low status) is due to factors like material deprivation, much will relate to observing one's low status in relation to 
others (i.e., the central idea of SSS): "poor health is not so much the outcome of being poor, but of feeling poor, that is, feeling poorer than others" (Saplosky, 2004, p. 410). While it must be remembered that the present study included no self-report measures of pain or stress, other work supports the idea that the stressfulness of one's relatively low SSS can promote ill-health.

For instance, Cohen et al.'s (2008) work indicated that the low SSS-cold susceptibility relationship may be partially mediated by poor sleep (a common stress symptom), while Gianaros et al. (2007) suggest that the reduced grey matter they observed in low SSS participants may be due to stress remodelling the brain. Moreover, Adler et al (2000) concluded that low SSS either increases stress or vulnerability to stress.

This tentatively suggests that the SSS-analgesic prescriptions relationship in the current study may also be partially due to the stress of low relative status. It is wellestablished that prolonged stress response activation- particularly likely in cases of chronic stress, such as when one permanently possesses relatively low status- can promote body tissue breakdown, producing chronic pain (e.g., Melzack, 1999). This might explain why SSS still significantly predicted the odds of being prescribed analgesics even after accounting for OSS.

There may be other explanations for our findings, however. For instance, participants reporting higher SSS could experience more optimism, while participants reporting lower SSS could experience more pessimism, both of which can affect wellbeing (e.g., Peterson \& Bossio, 1991). Future work could perhaps thus examine how SSS relates to both stress and hope.

\section{Limitations and Future Directions}

Analgesics Measure 
Our study has limitations. Some relate to our analgesics measure, which, while it has the advantage of being objective, is not problem-free. Perhaps most importantly, we cannot assume there is a direct relationship between analgesic prescriptions and pain. Patients can use analgesics in unlicensed ways for reasons other than pain, such as for depression, or due to addiction: issues that may be particularly prevalent amongst lower-status individuals. It is also possible that the GPs involved in this study simply prescribe more analgesics to those of lower social status, regardless of pain experienced- the GPs in this study only comprise $0.51 \%$ of Scottish GP surgeries, so they may not represent typical prescription practices. However, the fact that all Scottish GP surgeries are required to comply with prescribing indicators and be aware of drug-seeking behaviour reduces the likelihood of such events occurring.

On the other hand, it is true that not all individuals experiencing pain request analgesics. Indeed, Papageorgiou et al. (1997) found that those dissatisfied with their work were particularly likely to report backache for which they did not seek medical assistance. Some individuals will self-medicate, or simply rest the affected area: perhaps those with high social status are most able to afford to do this. Since such techniques are particularly suited to relatively minor/acute pain, it could be that participants who received analgesic prescriptions in the present study were more likely to have more severe/chronic pain. Future research could investigate this.

There are other limitations to our analgesics measure. Importantly, it does not allow conclusions to be drawn regarding participants' overall health. It is possible to experience some types of chronic pain (e.g., rheumatism), but still consider oneself to be healthy. Moreover, it reveals nothing about the cause or perceived severity of pain, and it does not differentiate between chronic and acute pain. Finally, it does not consider the extent to which individuals' lives are affected by pain. As discussed, low OSS individuals tend to be more 
disabled by pain (Dorner et al., 2011; Portenoy, Ugarte, Fuller, \& Haas, 2004), and experience lower life quality (Gerstle et al., 2001). Overall, these limitations suggest that future research should perhaps include subjective measures of pain and general health, whilst still including analgesic prescriptions as an objective measure. In order to understand more about the analgesics-health relationship, it would be particularly interesting to consider the extent to which 'healthy' people obtain analgesic prescriptions (e.g., after accidents).

\section{SSS Measure}

Considering our SSS measure, nearly half of participants placed themselves in the highest category, while only $7 \%$ placed themselves in the lowest. While the point of SSS is to allow individuals to assess their own status, it is likely that our sample (and probably the population) has a somewhat unbalanced opinion of status, with people being more willing to claim they have a higher status then perhaps they do. While this could be a potential issue, it should be remembered that SSS is entirely subjective, so results are probably unlikely to be normally distributed.

Although other variables within the logistic regression model were stronger predictors of analgesic prescriptions than SSS, the results indicate that SSS continues to be an important variable in the model once these other variables are taken into account. For instance, although the model reveals Occupational Status to be an important predictor, additional analyses revealed that when the sample was divided into employed and unemployed participants, SSS remained a significant predictor in both sub-groups. Thus, while OSS-related and demographic variables do have important effects upon analgesic prescriptions, SSS plays an important and unique predictive role.

A further limitation is that the study is cross-sectional, so it is difficult to establish whether low SSS actually causes pain. Two competing hypotheses have been forwarded to 
explain the OSS-pain relationship: i) the social causation hypothesis- low SES causes pain, and ii) the social selection hypothesis- the disabling effects of pain cause low SES (e.g., Işı1k et al., 2009). Generally, research supports the former hypothesis (e.g., Wiendels et al., 2006; Hagen et al., 2002), and we agree in the context of the SSS-pain relationship. However, a longitudinal design is required to draw firm conclusions, and we hope Wave 2 will enable this.

\section{Conclusions}

Our results offer the first evidence to suggest that SSS has important effects on pain that go beyond the influence of OSS. Further research is required in order to untangle the potential reasons for this finding, and to consider how it might help to improve wellbeing. For instance, OSS undoubtedly has an important role to play in health, but policies designed to enhance OSS (e.g., training schemes) are also likely to achieve something less tangible: to make people feel that they are no longer on the bottom rung of life's ladder. Our findings suggest that this is a significant shift in its own right, which could have important painreducing and health-enhancing effects, ultimately allowing such individuals the chance of better life quality. 


\section{References}

Adler, N. E., Epel, E. S., Castellazzo, G., \& Ickovics, J. R. (2000). Relationship of subjective and objective social status with psychological and physiological functioning: Preliminary data in healthy white women. Health Psychology, 19, 586-592. doi: 10.1037//0278-6133.19.6.586.

Adler, N., Singh-Manoux, A., Schwartz, J., Stewart, J., Matthews, K., \& Marmot, M. G. (2008). Social status and health: a comparison of British civil servants in Whitehall-II with European- and African-Americans in CARDIA. Social Science \& Medicine, 66, 1034-1045. doi: 10.1016/j.socscimed.2007.11.031.

Adler, N. E., \& Snibbe, A. C., (2003). The role of psychosocial processes in explaining the gradient between socioeconomic status and health. Current Direction in Psychological Science, 12, 119-123. doi: 10.1111/1467-8721.01245.

Aggarwal, V. R., Macfarlane, T. V., \& Macfarlane, G. J. (2003). Why is pain more common amongst people living in areas of low socio-economic status? A population-based cross-sectional study. British Dental Journal, 194, 383-387. doi: 10.1038/sj.bdj.4810004.

Chen, E., \& Paterson, L. Q. (2006). Neighborhood, family, and subjective socioeconomic status: How do they relate to adolescent health? Health Psychology, 25, 704-714. doi: 10.1037/0278-6133.25.6.704.

Cohen, S., Alper, C. M., Doyle, W. J., Adler, N., Treanor, J. J., \& Turner, R. B. (2008). Objective and subjective socioeconomic status and susceptibility to the common cold. Health Psychology, 27, 268-274. doi: 10.1037/0278-6133.27.2.268. 
Davis, J. A. (1956). Status symbols and the measurement of status perception. Sociometry, 19, 154-165. doi: 10.2307/2785629.

Devoino, L., Alperina, E., Kudryavtseva, N., \& Popova, N. (1993). Immune responses in male mice with aggressive and submissive behavior patterns: Strain differences. Brain, Behavior and Immunity, 7, 91-96. doi: 10.1006/brbi.1993.1009.

Dorner, T. E., Muckenhuber, J., Stronegger, W. J., Ràsky, É., Gustorff, B., \& Freidl, W. (2011). The impact of socio-economic status on pain and the perception of disability due to pain. European Journal of Pain, 15, 103-109. doi: 10.1016/j.ejpain.2010.05.013.

Eisermann, K. (1992). Long-term heart rate responses to social stress in wild European rabbits: Predominant effect of rank position. Physiology \& Behavior, 52, 33-36. doi: 10.1016/0031-9384(92)90430-A.

Fuentes, M., Hart-Johnson, T., \& Green, C. R. (2007). The association among neighbourhood socioeconomic status, race, and chronic pain in Black and White older adults. Journal of the National Medical Association, 99, 1160-1169.

Gerstle, D. S., All, A. C., \& Wallace, D. C. (2001). Quality of life and chronic non-malignant pain. Pain Management Nursing, 2, 98-109. doi: 10.1053/jpmn.2001.24716.

Gianaros, P. J., Horenstein, J. A., Cohen, S., Matthews, K. A., Brown, S. M., Flory, J. D.,... Hariri, A. R. (2007). Perigenual anterior cingulate morphology covaries with perceived social standing. Scan, 2, 161-173. doi: 10.1093/scan/nsm013.

Goodman, E., Adler, N. E., Daniels, S. R., Morrison, J. A., Slap, G. B., \& Dolan, L. M. (2003). Impact of objective and subjective social status on obesity in a biracial cohort of adolescents. Obesity Research, 11, 1018-1026. doi: 10.1038/oby.2003.140. 
Goodman, E., Adler, N. E., Kawachi, I., Frazier, A. L., Huang, B., \& Colditz, G. A. (2001). Adolescents' perceptions of social status: Development and evaluation of a new indicator. Pediatrics, 198, 31-38. doi: 10.1542/peds.108.2.e31.

Hagen, K., Vatten, L., Stovner, L. J., Zwart, J. A., Krokstad, S., \& Bovim, G. (2002). Low socio-economic status is associated with increased risk of frequent headache: A prospective study of 22718 adults in Norway. Cephalalgia, 22, 672-679. doi: 10.1046/j.1468-2982.2002.00413.x.

Honjo, K., Kawakami, N., \& Tsuchiya, M. (2014). Association of subjective and objective socioeconomic status with subjective mental health and mental disorders among Japanese men and women. International Journal of Behavioral Medicine, 21, 421429. doi: 10.1007/s12529-013-9309-y.

Işık, U., Topuzoğlu, A., Ay, P., Ersu, R. H., Arman, A. R., Önsüz,...Dağlı, E. (2009). The prevalence of headache and its association with socioeconomic status among schoolchildren in Istanbul, Turkey. Headache: The Journal of Head and Face Pain, 49, 697-703. doi: 10.1111/j.1526-4610.2009.01339.x.

Joint Formulary Committee (2012). British National Formulary (64 $4^{\text {th }}$ ed.). London: BMJ Group and Pharmaceutical Press.

Macleod, J., Smith, G. D., Metcalfe, C., and Hart, C. (2005). Is subjective social status a more important determinant of health than objective social status? Evidence from a prospective observational study of Scottish men. Social Science \& Medicine, 61, 1916-1929. doi: 10.1016/j.socscimed.2005.04.009.

Melzack, R. (1999). Pain and stress: A new perspective. In R. J. Gatchel \& D. C. Turk (Eds.). Psychosocial factors in pain (pp. 89-106). New York: Guilford Press. 
Ostrove, J. M., Adler, N. E., Kupperman, M., \& Washington, A. E. (2000). Objective and subjective assessments of socioeconomic status and their relationship to self-rated health in an ethnically diverse sample of pregnant women. Health Psychology, 19, 613-618. doi: 10.1037//0278-6133.19.6.613.

Papageorgiou, A. C., Macfarlane, G. J., Thomas, E., Croft, P., Jayson, M. I. V., \& Silman, A. J. (1997). Psychosocial factors in the workplace-do they predict new episodes of low back pain? Evidence from the South Manchester back pain study. Spine, 22, 11371142.

Peterson, C., \& Bossio, L. M. (1991). Health and optimism. New York: Free Press.

Portenoy, R. K., Ugarte, C., Fuller, I., \& Haas, G. (2004). Population-based survey of pain in the United States: Differences among White, African American, and Hispanic subjects. The Journal of Pain, 5, 317-328. doi: 10.1016/j.jpain.2004.05.005.

Saastamoinen, P., Leino-Arjas, P., Laaksonen, M., \& Lahelma, E. (2005). Socio-economic differences in the prevalence of acute, chronic and disabling chronic pain among ageing employees. Pain, 114, 364-371. doi: 10.1016/j.pain.2004.12.033.

Sani, F., Madhok V., Norbury, M., Dugard, P., \& Wakefield, J. R. H. (2014). High identification with social groups is associated with healthier behaviour: Evidence from a Scottish community sample. British Journal of Health Psychology. doi: 10.1111/bjhp.12119.

Saplosky, R. M. (2004). Social status and health in humans and other animals. Annual Review of Anthropology, 33, 393-418. doi: 10.1146/annurev.anthro.33.070203.144000.

Scottish Government (2012). Scottish Index of Multiple Deprivation 2012. Edinburgh: National Statistics Publication for Scotland, Scottish Government. 
SIGN: Scottish Intercollegiate Guidelines Network (2013). Management of chronic pain: SIGN publication no. 136. Edinburgh: SIGN.

Singh-Manoux, A., Adler, N. E., \& Marmot, M. G. (2003). Subjective social status: Its determinants and its association with measures of ill-health in the Whitehall II study. Social Science \& Medicine, 56, 1321-1333. doi: 10.1016/S0277-9536(02)00131-4.

Singh-Manoux, A., Marmot, M. G., \& Adler, N. E. (2005). Does subjective social status predict health and change in health status better than objective status? Psychosomatic Medicine, 67, 855-861. doi: 10.1097/01.psy.0000188434.52941.a0.

Soares, J., F., \& Grossi, G. (1999). Psychosocial factors, pain parameters, mental health and coping among Turkish and Swedish patients with musculoskeletal pain. Scandinavian Journal of Occupational Therapy, 6, 174-183. doi: 10.1080/110381299443654.

Wiendels, N. J., Neven, A. K., Rosendaal, F. R., Spinhoven, P., Zitman, F. G., Assendelft, W. J. J., \& Ferrari, M. D. (2006). Chronic frequent headache in the general population: Prevalence and associated factors. Cephalalgia, 26, 1434-1442. doi: 10.1111/j.14682982.2006.01210.x.

Winter, A. C., Berger, K., Buring, J. E., \& Kurth, T. (2011). Associations of socioeconomic status with migraine and non-migraine headache. Cephalalgia, 32, 1590-170. doi: $10.1177 / 0333102411430854$.

Wright, C.E., \& Steptoe, A. (2005). Subjective socioeconomic position, gender and cortisol responses to waking in an elderly population. Psychoeuroendocrinology, 30, 582-590. doi: 10.1016/j.psyneuen.2005.01.007. 
Table 1. Frequencies and percentages for the Analgesics variable at each level of Subjective Social Status (1-3), including the chi-square value

\begin{tabular}{|c|c|c|}
\hline \multirow{3}{*}{$\begin{array}{l}\text { Subjective } \\
\text { Social Status }\end{array}$} & \multicolumn{2}{|c|}{ Analgesics } \\
\hline & No & Yes \\
\hline & & \\
\hline 1 & 99 & 33 \\
\hline$(n=132)$ & $75.00 \%$ & $25.00 \%$ \\
\hline 2 & 586 & 177 \\
\hline$(n=763)$ & $76.80 \%$ & $23.20 \%$ \\
\hline 3 & 738 & 140 \\
\hline$(n=878)$ & $84.05 \%$ & $15.95 \%$ \\
\hline & $2, N=1$ & $.04 ; p<$ \\
\hline
\end{tabular}

Note. 42 participants had a missing value for Subjective Social Status. These cases are excluded from this table. Moreover, 9 additional participants had a value for Subjective Social Status, but had a missing value for Analgesics. Again, these cases are excluded from this table. 
Table 2. Frequencies and percentages for the Analgesics variable at each level of the categorical control variables (Gender, Education, Occupational Status, and GP Surgery), including chi-square values

\begin{tabular}{|c|c|c|c|}
\hline & & \multicolumn{2}{|c|}{ Analgesics } \\
\hline & & No & Yes \\
\hline \multirow[t]{5}{*}{ Gender } & Female $(n=1046)$ & 835 & 211 \\
\hline & & $79.83 \%$ & $20.17 \%$ \\
\hline & Male $(n=769)$ & 621 & 148 \\
\hline & & $80.75 \%$ & $19.25 \%$ \\
\hline & & $\chi^{2}(1, N=1$ & $24 ; p=.62$ \\
\hline \multirow[t]{5}{*}{ Education } & Up to high school $(n=657)$ & 472 & 185 \\
\hline & & $71.84 \%$ & $28.16 \%$ \\
\hline & Above high school $(n=1145)$ & 974 & 171 \\
\hline & & $85.07 \%$ & $14.93 \%$ \\
\hline & & $\chi^{2}(1, N=18$ & $.05 ; p<.001$ \\
\hline Occupational & Not Employed $(n=925)$ & 664 & 261 \\
\hline \multirow[t]{4}{*}{ Status } & & $71.78 \%$ & $28.22 \%$ \\
\hline & Employed $(n=887)$ & 789 & 98 \\
\hline & & $88.95 \%$ & $11.05 \%$ \\
\hline & & $\chi^{2}(1, N=1 \varepsilon$ & $.00 ; p<.001$ \\
\hline GP Surgery & Location $1(n=157)$ & 114 & 43 \\
\hline (lowest to & & $72.61 \%$ & $27.39 \%$ \\
\hline \multirow[t]{5}{*}{ highest status) } & Location $2(n=993)$ & 759 & 234 \\
\hline & & $76.44 \%$ & $23.56 \%$ \\
\hline & Location $3(n=665)$ & 583 & 83 \\
\hline & & $87.67 \%$ & $12.33 \%$ \\
\hline & & $\chi^{2}(2, N=18$ & $.95 ; p<.001$ \\
\hline
\end{tabular}


Note. 13 participants had a missing value for Education, and 3 participants had a missing value for Occupational Status. These cases are excluded from this table. Moreover, 9 participants had a value for Gender, Education, Occupational Status, and GP Surgery, but had a missing value for Analgesics. Again, these cases are excluded from this table. 
Table 3. Correlations between the variables appearing in the logistic regression.

\begin{tabular}{|c|c|c|c|c|c|c|}
\hline Variable & 1 & 2 & 3 & 4 & 5 & 6 \\
\hline 1. Subjective Social Status (1-3) & - & & & & & \\
\hline 2. Age (years) & $.10 * * *$ & - & & & & \\
\hline 3. Gender $(0 / 1)$ & .03 & $.12 * * *$ & - & & & \\
\hline 4. Education $(0 / 1)$ & $.26 * * *$ & $-.20 * * *$ & $-.07 * *$ & - & & \\
\hline 5. Occupational Status $(0 / 1)$ & .03 & $-.59 * * *$ & -.02 & $.17 * * *$ & - & \\
\hline 6. GP Surgery $(1 / 2 / 3)-$ lowest to highest status & $.16^{* * *}$ & .04 & .01 & $.14 * * *$ & .02 & - \\
\hline
\end{tabular}

$* * p<.01 ; * * * p<.001$ 
Table 4. Summary of logistic regression analysis for variables predicting Analgesics

\begin{tabular}{|c|c|c|c|c|c|c|c|c|}
\hline \multirow[t]{2}{*}{ Variable } & \multirow[t]{2}{*}{ B } & \multirow[t]{2}{*}{$\mathrm{SE}$} & \multirow[t]{2}{*}{$\mathrm{R}$} & \multirow[t]{2}{*}{$\begin{array}{l}\text { Wald } \\
\text { statistic }\end{array}$} & \multirow[t]{2}{*}{$p$} & \multirow[t]{2}{*}{$\begin{array}{l}\text { Odds } \\
\text { ratio }\end{array}$} & \multicolumn{2}{|c|}{$\begin{array}{c}95 \% \text { CI for Odds } \\
\text { Ratio }\end{array}$} \\
\hline & & & & & & & Lower & Upper \\
\hline Subjective Social Status (1-3) & -.22 & .10 & -.05 & $4.47 *$ & .03 & 0.80 & .66 & .98 \\
\hline Age (years) & .02 & .01 & .07 & $6.90 * *$ & .009 & 1.02 & 1.00 & 1.03 \\
\hline Gender $(0 / 1)$ & -.15 & .13 & -.03 & 1.40 & .24 & 0.86 & 0.67 & 1.11 \\
\hline Education $(0 / 1)$ & -.49 & .13 & -.09 & $13.57 * * *$ & $<.001$ & 0.61 & 0.47 & 0.80 \\
\hline Occupational Status $(0 / 1)$ & -.85 & .16 & -.12 & $27.10^{* * *}$ & $<.001$ & 0.43 & 0.31 & 0.59 \\
\hline GP Surgery $(1 / 2 / 3)$ & -.52 & .11 & -.12 & $23.58 * * *$ & $<.001$ & 0.60 & 0.48 & 0.74 \\
\hline
\end{tabular}

